\title{
Achados fundoscópicos em crianças portadoras de anemia falciforme no estado do Rio Grande do Norte
}

\author{
Fundoscopic findings in children with sickle cell hemoglobinopathy in Rio Grande do \\ Norte state
}

\author{
Carlos Alexandre de Amorim Garcia ${ }^{1}$ \\ Maria Zélia Fernandes ${ }^{2}$ \\ Uchoandro Bezerra Costa Uchôa ${ }^{3}$ \\ Bruno de Morais Cavalcante ${ }^{3}$ \\ Raquel Araújo Costa Uchôa ${ }^{4}$
}

\begin{tabular}{l} 
RESUMO \\
\hline Objetivos: Detectar os principais achados fundoscópicos em crianças \\
portadoras de hemoglobinopatias falciformes. Métodos: Foram estudados \\
26 pacientes com hemoglobinopatias falciformes, no Serviço de Oftalmolo- \\
gia do Hospital Universitário Onofre Lopes, Natal, RN, que foram subme- \\
tidos a protocolo de pesquisa pré-estabelecido. Os resultados foram \\
avaliados estatisticamente pelo teste qui-quadrado. Resultados: A idade \\
média foi de 10,6 anos, com acuidade visual igual ou melhor que $20 / 25$ na \\
maioria, excetuando-se 3 olhos, que apresentavam outras doenças asso- \\
ciadas. Otipo mais freqüente foi o SS com $57,7 \%$ (15/26) dos casos, seguido \\
pelos SCe SA com $15,4 \%$ (4/26) cada, e pelo S-Thal com $11,5 \%$ (3/26). A \\
freqüência da retinopatia por células falciformes foi maior após os 10 anos \\
de idade, sendo mais freqüente, em valores relativos, no tipo S-Thal (100\% \\
dos casos) e, em valores absolutos, no tipo SS (9 casos). Os dois achados \\
mais comuns foram tortuosidade venosa(12/26) e "black sunburst” (7/26). \\
Conclusões: Observamos que a incidência de retinopatia por células \\
falciformes aumentou após os 10 anos de idade e não evidenciamos \\
achados da doença proliferativa. Portanto, enfatizamos a necessidade do \\
exame oftalmológico precoce nos portadores de anemia falciforme, como \\
forma de prevenir futuras complicações oculares.
\end{tabular}

Descritores: Anemia falciforme/diagnóstico; Hemoglobinopatias; Fundo de olho; Doença da hemoglobina C/diagnóstico; Doença da hemoglobina SC/diagnóstico; Doenças retinianas; Criança
Trabalho realizado no Serviço de Oftalmologia do Hospital Universitário Onofre Lopes, UFRN, Natal - RN Professor Adjunto IV de Oftalmologia da Universidade Federal do Rio Grande do Norte (UFRN); Coordenador da Residência Médica em Oftalmologia do Hospital Universitário Onofre Lopes (HUOL) - Universidade Federal do Rio Grande do Norte.

2 Professora Adjunta IV em Pediatria da Universidade Federal do Rio Grande do Norte; Coordenadora do Serviço de Onco-hematologia Pediátrica do Hospital de Pediatria da Universidade Federal do Rio Grande do Norte e do Hospital Infantil Varela Santiago, Natal-RN. ${ }^{3}$ Médicos Ex-residentes em Oftalmologia do Hospital Universitário Onofre Lopes - Universidade Federal do Rio Grande do Norte.

${ }^{4}$ Médica Residente do I ano em Oftalmologia do Hospital Universitário Onofre Lopes - Universidade Federal do Rio Grande do Norte.

Endereço para correspondência: Rua Ceará Mirim, 316 - Natal (RN) CEP 59020-240.

E-mail: prontoc.de.olhos@digi.com.br

Recebemos para publicação em 02.10.2001

Aceito para publicação em 21.02.2002

\section{INTRODUÇÃOO}

As hemoglobinopatias falciformes são um grupo de doenças hereditárias $^{(1)}$, que ocorrem principalmente na população negra ${ }^{(2)}$, pela formação anormal das hemoglobinas. As alterações podem ser qualitativas no caso da $\mathrm{HbS}$ e da $\mathrm{HbC}$ quando o ácido glutâmico da posição 6 da cadeia beta é substituído pela valina e lisina respectivamente ou, quantitativas quando há formação de um menor número de determinada cadeia como no caso das talassemias. Os genótipos mais comuns são o tipo homozigótico (SS), o heterozigótico ou traço falcêmico (SA), o associado à hemoglobina $\mathrm{C}(\mathrm{SC})$, e o associado à talassemia $(\mathrm{S}-\mathrm{Thal})^{(1)}$.

Tais hemoglobinopatias apresentam um quadro retiniano e vítreo característicos, associados às manifestações clínicas sistêmicas, tais como, anemia e fenômenos vaso-oclusivos ${ }^{(1)}$.

Herrik, em $1910^{(2)}$, iniciou o estudo sobre hemoglobinopatias descrevendo o formato peculiar das hemácias em um paciente negro, com anemia, artrite e dor abdominal. Posteriormente, Hann, Gillespie ${ }^{(3)}$ demonstraram 
que a transformação da hemácia normal em drepanócito ocorria com a queda da tensão do oxigênio. Em 1923, Taliaferro, Huck $^{(4)}$ determinaram que a doença falciforme é a expressão homozigótica de um gene. Em 1930, Cook $^{(5)}$ descreveu pela primeira vez as alterações fundoscópicas na anemia falciforme, que só foram confirmadas em 1954, por Henry, Chap$\operatorname{man}^{(6)}$. Sua ligação ao genótipo SC foi comprovada em 1956, por Hannon ${ }^{(7)}$; em 1957, por Goodman ${ }^{(8)}$ et al., e em 1959, por Lieb et al. ${ }^{(9)}$.

As manifestações oculares são representadas por alterações orbitárias, conjuntivais, uveais, papilares e retinianas ${ }^{(10-11)}$. Com relação às alterações retinianas, podemos dividir a retinopatia por células falciformes em não proliferativa e proliferativa ${ }^{(1,10)}$. Dentre as formas de anemia falciforme, os pacientes do tipo SS apresentam quadro clínico sistêmico mais severo do que os do tipo SC. Por outro lado, os efeitos oclusivos oculares são mais predominantes no tipo SC, que possuem anemia apenas moderada e maior viscosidade sangüínea ${ }^{(1,12)}$.

A retinopatia não proliferativa pode cursar com alguns achados, tais como: tortuosidade venosa, em até $50 \%$ na doença homozigótica ${ }^{(1)}$; sinais ligados a oclusão vascular e hemorragias chamadas "salmon patch" e "black sunburst", sendo ambos mais freqüentes no tipo SC; aparência esbranquiçada na periferia da retina (isquemia); alterações maculares, sendo mais relacionadas ao tipo SS; estrias angióides, que podem chegar até $22 \%$ em pessoas acima de 40 anos; alterações no nervo óptico, tais como, pontos escuros, pequenos e vermelhos, que são mais freqüentes no tipo SS; e outras alterações, como oclusão da artéria central da retina ${ }^{(1)}$, buracos retinianos e membrana epiretiniana ${ }^{(13)}$.

Segundo a fisiopatologia proposta por Goldberg ${ }^{(14)}$ e Romayananda ${ }^{(15)}$ a seqüência de eventos inicia-se pela oclusão arteriolar na periferia da retina e conseqüente novo arranjo dos capilares adjacentes. Estes podem dilatar e formar comunicações artério-venosas, com a formação de neovasos entre a retina vascular e avascular. Hemorragias de neovasos da retina e do espaço vítreo podem estimular a formação de proliferação fibroglial do novo tecido formado. Repetidas hemorragias no vítreo podem acarretar tração sobre a retina, originando retinosquises e descolamento tracional ${ }^{(1,12)}$.

Goldberg classificou a retinopatia proliferativa em 5 está$\operatorname{dios}:^{(1,12)}$.

I - Oclusões arteriolares na periferia da retina;

II - Anastomoses artério-venosas na periferia da retina;

III - Proliferações fibrosas e neovasculares;

IV - Hemorragias no vítreo;

$\mathrm{V}$ - Descolamento de retina.

O objetivo deste trabalho é detectar os principais achados fundoscópicos em crianças portadoras de hemoglobinopatias falciformes, examinadas no Hospital Universitário Onofre Lopes (HUOL), Natal, Rio Grande do Norte.

\section{MÉTODOS}

Foram estudados 26 pacientes portadores de hemoglobinopatias, durante o período de agosto de 1998 a agosto de 2000, no Serviço de Oftalmologia, do Hospital Universitário Onofre Lopes (HUOL), Universidade Federal do Rio Grande do Norte (UFRN). Todos os pacientes foram encaminhados pelo Serviço de Hematologia Pediátrica do Hospital Infantil Varela Santiago e Hospital Pediatria da UFRN, portando seus respectivos tipos de hemoglobinopatias já confirmados pelo teste de eletroforese de hemoglobina em $\mathrm{pH}$ alcalino, onde se qualificam e quantificam as hemoglobinas normais e anormais.

Foi instituído um protocolo de pesquisa pré-estabelecido contendo: identificação completa, tipo de hemoglobinopatia, exame oftalmológico completo: 1) medida de acuidade visual com a melhor correção óptica pela tabela de Snellen; 2) exame ocular externo; 3) biomicroscopia do segmento anterior; 4) tonometria de aplanação; 5) exame fundoscópico sob midríase, incluindo oftalmoscopia binocular indireta e biomicroscopia com lente de Goldmann; 6) retinografia e angiofluoresceinografia nos casos com alterações fundoscópicas.

Os resultados foram submetidos a análise estatística com o teste Qui-quadrado $\left(\chi^{2}\right)$ com nível de significância de até 5\%.

\section{RESULTADOS}

Foram estudados 26 pacientes: 11 do sexo masculino $(42,3 \%)$ e 15 do feminino $(57,7 \%)$, num total de 52 olhos.

Em relação ao grupo étnico, houve predominância estatisticamente significante $(p=0,01)$ da cor parda, com $18(69,2 \%)$ pacientes, seguida pelos brancos com $6(23,1 \%)$ e pelos negros com $2(7,7 \%)$. A faixa etária variou de 4 a 16 anos, com média de 10,61 anos.

A acuidade visual corrigida foi melhor ou igual a 20/25 em 49 olhos (94,2\%), e pior ou igual a 20/200 em 3 olhos (6,7\%). Destes, dois apresentavam atrofia do nervo óptico e um era afácico, decorrente de facectomia após catarata congênita, não havendo relação com retinopatia por células falciformes.

Quanto à incidência dos tipos de hemoglobinopatias, o mais freqüente foi o tipo SS com 15 (57,7\%) pacientes, seguido pelos tipos SC e SA com $4(15,4 \%)$ pacientes cada, e pelo tipo S-Thal com $3(11,5 \%)$ pacientes, sendo a diferença de incidência do tipo SS sobre os demais estatisticamente significante ( $\mathrm{p}$ $=0,02)$ (Tabela 1$)$.

Observarmos na Tabela 2 que a incidência de patologia retiniana foi maior no grupo de faixa etária mais elevada (acima de 10 anos) e menor no grupo mais jovem (abaixo de 10 anos), sendo tal diferença estatisticamente significante $(p=0,015)$.

Com relação ao percentual de patologia retiniana e o tipo de hemoglobinopatia, verificamos que esteve presente em $100 \%$ dos casos do tipo S-Thal, $75 \%$ dos casos do tipo SC, $75 \%$ dos casos do tipo SA e $60 \%$ dos casos do tipo SS, conforme demonstrado na Tabela 3. 


\begin{tabular}{|lcc|}
\hline \multicolumn{3}{|c|}{ Tabela 1. Incidência das hemoglobinopatias no total de } \\
crianças & estudadas \\
Tipos de hemoglobinopatias & $\mathbf{n}^{\circ}$ pacientes & $\%$ \\
SS & 15 & 57,7 \\
SC & 4 & 15,4 \\
SA & 4 & 15,4 \\
S-THAL & 3 & 11,5 \\
Total & 26 & 100,0 \\
Nota: Observa-se incidência significativamente maior da hemoglobinopatia SS \\
em relação às demais $(p=0,02)$
\end{tabular}

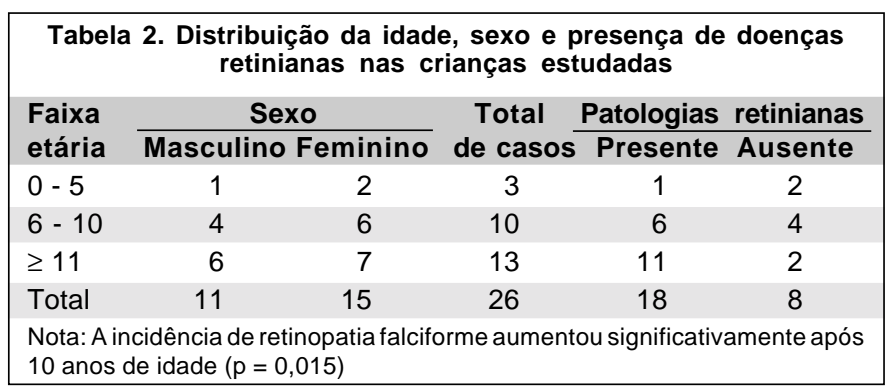

Conforme Tabela 4, detectamos seis padrões distintos de lesões retinianas por ordem crescente de aparecimento: tortuosidade venosa em 12 pacientes; lesões tipo "black sunburst" em 7 pacientes (Figura 1); anastomoses vasculares em 2 pacientes; e hemorragia tipo "salmon patch" (Figura 2), oclusões periféricas e branco sem pressão em 1 paciente cada. Foi diagnosticado 1 caso de palidez isolada do nervo óptico e 1 caso com lesões hiperpigmentadas em retina inferior, ambos pertencentes ao tipo SS, além de 1 caso de neurorretinite subaguda difusa unilateral (DUSN), pertencente ao tipo SA (Tabela 4).

As lesões tipo tortuosidade venosa e hemorragia "black sunburst" foram mais freqüentes no tipo SS. O único caso de hemorragia "salmon patch" foi evidenciado no tipo SA.

$\mathrm{O}$ caso de oclusões periféricas e o de branco sem pressão foram encontrados apenas no tipo S-Thal. Houve 2 casos de anastomoses vasculares, sendo 1 no tipo SS e 1 no tipo SA (Tabela 4).

Não foram observadas complicações oculares decorrentes da retinopatia por células falciformes, neste estudo, tais como hemorragia vítrea ou descolamento de retina.

\begin{tabular}{|c|c|c|c|c|c|}
\hline \multirow{3}{*}{$\begin{array}{l}\text { Tipos de } \\
\text { hemoglobinopatia }\end{array}$} & \multirow{3}{*}{$\begin{array}{c}\text { Total de } \\
\text { casos }\end{array}$} & \multicolumn{4}{|c|}{ Patologia retiniana } \\
\hline & & \multicolumn{2}{|c|}{ Presente } & \multicolumn{2}{|c|}{ Ausente } \\
\hline & & $\mathbf{N}$ & $\%$ & $\mathbf{N}$ & $\%$ \\
\hline SS & 15 & 9 & 60 & 6 & 40 \\
\hline SC & 4 & 3 & 75 & 1 & 25 \\
\hline SA & 4 & 3 & 75 & 1 & 25 \\
\hline S-THAL & 3 & 3 & 100 & - & 0 \\
\hline Total & 26 & 18 & & 8 & \\
\hline
\end{tabular}

\begin{tabular}{|c|c|c|c|c|c|}
\hline Tipo de lesão & SS & SC & SA & S-Thal & Total \\
\hline Tortuosidade venosa & 6 & 2 & 3 & 1 & 12 \\
\hline "Black sunburst" & 5 & 1 & - & 1 & 7 \\
\hline "Salmon patch" & - & - & 1 & - & 1 \\
\hline Oclusões periféricas & - & - & - & 1 & 1 \\
\hline Anastomoses & 1 & - & 1 & - & 2 \\
\hline Branco sem pressão & - & - & - & 1 & 1 \\
\hline Outros & $2^{*}$ & - & $1^{* *}$ & - & 3 \\
\hline
\end{tabular}

\section{DISCUSSÃO}

Nesta série de casos, evidenciamos que a hemoglobinopatia falciforme mais freqüente foi o tipo SS com 57,7\% (15/26) do total, seguido pelos tipos SC e SA com 15,4\% (04/26) cada, e S-Thal com $11,5 \%$ (3/26) dos casos; semelhante ao encontrado em outros estudos da literatura ${ }^{(10-12)}$.

A freqüência de retinopatia foi maior no grupo de faixa etária acima de 10 anos, semelhante a outros estudos ${ }^{(16-18)}$, alertando para a importância do exame oftalmológico precoce e periódico em pacientes portadores de hemoglobinopatias.

Conforme os estudos de Gonçalves et al. ${ }^{(10)}$ e Talbot et al. ${ }^{(17)}$, a retinopatia não proliferativa é mais freqüente nos pacientes jovens, enquanto que a forma proliferativa ocorre numa faixa etária mais elevada, acima dos vinte anos de idade. De forma semelhante, não detectamos caso de retinopatia proliferativa, provavelmente pela baixa idade das crianças estudadas.

Evidenciamos em nosso estudo que a doença retiniana por células falciformes predominou, em valores absolutos, no tipo SS (09/15), semelhante ao trabalho de Gonçalves et al. ${ }^{(10),}$ Talbot et al. ${ }^{(17)}$ e Condon et al. ${ }^{(18)}$. Em valores relativos, tal retinopatia predominou no tipo S-Thal, com $100 \%$ dos casos, seguido pelos tipos SC e SA, com $75 \%$ cada, e pelo tipo SS, com $60 \%$. Tais achados foram semelhantes aos de outros trabalhos da literatura, como o de Gonçalves et al. ${ }^{(10)}$.

Dentre os principais achados fundoscópicos, podemos destacar, pela ordem de freqüência, a presença de: 1) tortuosidade venosa, sendo mais incidente no tipo SS, fato evidenciado em outros estudos ${ }^{(10,12)} ; 2$ ) lesão tipo "black sunburst", que pode ser decorrente de um processo reparativo após hemorragia pré, intra ou sub-retiniana ${ }^{(12)}$, sendo mais freqüente no tipo SS e inexistente no tipo SA, resultado semelhante ao encontrado de Gonçalves et al. ${ }^{(10)} ; 3$ ) hemorragia tipo "salmon patch", que pode se formar após oclusão e ruptura abrupta de uma arteríola retiniana de tamanho intermediário ${ }^{(1)}$, tendo ocorrido em 1 caso do tipo SA, não sendo encontrado semelhante achado na literatura pesquisada. O único caso de oclusão periférica ocorreu no tipo S-Thal, diferente de outros trabalhos da literatura ${ }^{(10,19-21)}$. Os demais achados, tais como anastomoses vasculares e branco sem pressão, tiveram baixa incidência, como era previsto. 
A literatura referente à anemia falciforme não oferece muitas informações sobre o quadro oftalmológico na população infantil.

\section{CONCLUSÕES}

O tipo de hemoglobinopatia mais freqüente neste estudo foi o grupo $\mathrm{SS}(\mathrm{p}=0,02)$.

Houve predominância da cor parda e do sexo feminino neste estudo, tendo o primeiro significância estatística $(p=0,01)$.

A incidência de patologia retiniana por células falciformes mostrou-se maior com o aumento da faixa etária após 10 anos $(\mathrm{p}=0,015)$.

A doença retiniana por células falciformes foi, em valores absolutos, maior no grupo $\mathrm{SS}$ e, em valores relativos, maior no grupo S-Thal.

Os achados fundoscópicos mais freqüentes foram tortuosidade venosa e hemorragia tipo "black sunburst", estando ambos mais relacionados ao tipo SS.

Apesar de não ter havido caso de retinopatia proliferativa por células falciformes no presente estudo, e da maioria dos pacientes apresentar boa acuidade visual final com correção, enfatizamos a necessidade de um exame oftalmológico precoce e acompanhamento periódico das crianças portadoras dessa patologia, principalmente após os 10 anos de idade, como medida de se evitar complicações oftalmológicas futuras.

\section{ABSTRACT}

Purpose: To point out the main fundoscopic findings in children with sickle cell trait hemoglobinopathies. Methods: We studied 26 patients with sickle cell hemoglobinopathies in the ophthalmological ward at the Hospital Universitário Onofre Lopes, Natal, RN. The patients were submitted to a research questionnaire and the results were statistically evaluated by the $\chi^{2}$ test. Results: The average age was 10,6 years, with visual acuity equal or better than $20 / 25$ in the majority, except for three eyes which presented other associated pathologies. The most frequent type was SS in 57.7\% (15/26) of cases, followed by SC e SA in $15.4 \%$ (4/26) each, and by SThal in $11.5 \%(3 / 26)$. The frequency of sickle cell retinopathy was higher after 10 years of age, being more frequent, in relative values, in type S-Thal (100\%) and, in absolute values, in type SS ( 9 cases). The two most common findings were venous tortuosity (12/26) and "black sunburst" (7/26). Conclusion: We observed that the incidence of retinopathy in sickle cell increased with age over 10 years and no evidence of proliferative disease was found. Therefore, we emphasize the need for early ophthalmological examination in carriers of sickle cell disease as a form of preventing future complications.

Keywords: Sickle cell disease/diagnosis; Hemoglobinopathies; Fundus oculi; Hemoglobin C disease/diagnosis; Hemoglobin SC disease/diagnosis; Retinal diseases; Children

\section{REFERÊNCIAS}

1. Bonanomi MTBC, Oliveira AA, Suzuki H. Hemoglobinopatias. In: Abujamra S, Ávila M, Barsante C 1. Retina e vítreo. São Paulo: Roca; 2000. p.592-601.

2. Herrick JB. Peculiar elongated and sickle-shaped red blood corpuscles in a case of severe anemia, 1910.Yale J Biol Med 2001;74:179-84.

3. Hahn EV, Gillespie EB. Sickle cell anemia. Report of a case greatly improved by splenectomy. Experimental study of sickle cell formation. Arch Intern Med 1927;39:233-54.

4. Taliaferro WH, Huck JG. The inheritance if sickle cell anemia in man. Genetics 1923;8:594-8.

5. Cook WC. A case of sickle cell anemia with associated subarachnoid hemorrhage. J Med 1930;11:541.

6. Henry MD, Chapman AZ. Vitreous hemorrhage and retinopathy associated with sickle cell disease. Am J Ophthalmol 1954;38:204-9.

7. Hannon JF. Vitreous hemorrhages associated with sickle cell-hemoglobin C disease. Am J Ophthalmol 1956;42:707-12.

8. Goodman G, Sallmann L, Holland MG. Ocular manifestations of sickle cell disease. Arch Ophthalmol 1957;58:655-82.

9. Lieb WA, Geeraets WJ, Guerry D. Sickle cell retinopathy. Ocular and systemic manifestations of sickle cell disease. Acta Ophthalmol 1959;58:1-45.

10. Gonçalves JCM, Braga JAP, Nione AS, Simoceli RA, Yamamoto M. Retinopatia falciforme em crianças. Arq Bras Oftalmol 1990;53:158-61.

11. Kansky JJ. Retinopathy in blood disorders. In: Kansky JJ. Clinical ophthalmology. Oxford: Butterworth-heinemann; 1994. p.370-4.

12. Oliveira FVP, Aihara T, Cançado RD. Alterações fundoscópicas nas hemoglobinopatias SS e SC. Arq Bras Oftalmol 1996;59:234-8.

13. Carney MD, Jampol LM. Epiretinal membranes in sickle cell retinopathy. Arch Ophthalmol 1987; 105:214-7.

14. Goldberg MF. Classification and pathogenesis of proliferative sickle cell retinopathy. Am J Ophthalmol 1971;71:649-65.

15. Romayananda N, Goldberg MF, Green WR. Histopathology of sickle cell retinopathy. Trans Am Acad Ophthalmol Otolaryngol 1973;77:OP642-76.

16. Fox PD, Dunn DT, Morris JS, Serjeant GR. Risk factors for proliferative sickle retinopathy. Br J Ophthalmol 1990;74:172-6.

17. Talbot JF, Bird AC, Maude G H, Acheson RW, Moriarty BJ, Serjeant GR. Sickle cell retinopathy in jamaican children: further observations from a cohort study. Br J Ophthalmol 1988;72:727-32.

18. Condon PI, Gray R, Serjeant GR. Ocular findings in children with sickle cell disease in Jamaica. Br J Ophthalmol 1974;58:644-9.

19. Bonanomi MT, Cunha, SL, Araújo JT. Fundoscopic alterations in SS and SC hemoglobinopathies: study of a Brazilian population. Ophthalmologica 1988;197:26-33.

20. Fox PD, Higgs DR, Serjeant GR. Influence of $\alpha$-thalassemia on the retinopathy of homozigous sickle cell disease. Br J Ophthalmol 1993;77:89-90.

21. Al-Hazza S, Bird AC, Kulozik A, Serjeant be, Serjeant GR, Thomas P, Padmos A. Ocular findings in Saudi Arabian patients with sickle cell disease. Br J Ophthalmol 1995; 79:457-61. 